Open Access

\title{
6-Mercaptopurine reduces cytokine and Muc5ac expression involving inhibition of NFkB activation in airway epithelial cells
}

\author{
Kondababu Kurakula ${ }^{1,2}$, Anouk A. Hamers ${ }^{1}$, Pieter van Loenen ${ }^{1}$ and Carlie J.M. de Vries ${ }^{1 *}$
}

\begin{abstract}
Background: Mucus hypersecretion and excessive cytokine synthesis is associated with many of the pathologic features of chronic airway diseases such as asthma. 6-Mercaptopurine (6-MP) is an immunosuppressive drug that is widely used in several inflammatory disorders. Although 6-MP has been used to treat asthma, its function and mechanism of action in airway epithelial cells is unknown.

Methods: Confluent NCI-H292 and MLE-12 epithelial cells were pretreated with 6-MP followed by stimulation with TNFa or PMA. mRNA levels of cytokines and mucins were measured by RT-PCR. Western blot analysis was performed to assess the phosphorylation of IKBa and luciferase assays were performed using an NFkB reporter plasmid to determine NFKB activity. Periodic Acid Schiff staining was used to assess the production of mucus.

Results: 6-MP displayed no effect on cell viability up to a concentration of $15 \mu \mathrm{M}$. RT-PCR analysis showed that 6-MP significantly reduces TNFa- and PMA-induced expression of several proinflammatory cytokines in NCl-H292 and MLE-12 cells. Consistent with this, we demonstrated that 6-MP strongly inhibits TNFa-induced phosphorylation of IKBa and thus attenuates NFKB luciferase reporter activity. In addition, 6-MP decreases Rac1 activity in MLE-12 cells. 6-MP down-regulates gene expression of the mucin Muc5ac, but not Muc2, through inhibition of activation of the NFkB pathway. Furthermore, PMA- and TNFa-induced mucus production, as visualized by Periodic Acid Schiff (PAS) staining, is decreased by 6-MP.
\end{abstract}

Conclusions: Our data demonstrate that 6-MP inhibits Muc5ac gene expression and mucus production in airway epithelial cells through inhibition of the NFKB pathway, and 6-MP may represent a novel therapeutic target for mucus hypersecretion in airway diseases.

Keywords: 6-MP, Epithelial cells, TNFa, Muc5ac, NFkB

\section{Background}

Chronic airway diseases such as asthma, chronic bronchitis, cystic fibrosis, and chronic allergic rhinitis are characterized by airway inflammation and mucus hypersecretion. Airway mucus is a component of the pulmonary innate immune function and plays a crucial role in defense against infectious and environmental agents [1-7]. Excessive mucus production is a hallmark in the pathogenesis of several airway diseases as it increases morbidity and mortality by obstructing mucocilary

\footnotetext{
* Correspondence: c.j.devries@amc.uva.nl

'Department of Medical Biochemistry, Academic Medical Center, University of Amsterdam, Meibergdreef 15, 1105 AZ Amsterdam, The Netherlands Full list of author information is available at the end of the article
}

clearance and air flow [8]. Goblet cells produce mucins, a class of mucus glycoproteins that provide airway with characteristic adhesiveness and viscoelasticity to maintain epithelium homeostasis [3]. To date, more than 20 mucin genes have been identified in airways. Among several mucin genes, Muc5ac is a major constituent of the mucous layer in the airways of humans with respiratory diseases and therefore serves as a marker for mucus cell hyperplasia $[9,10]$. Numerous previous studies reported that inflammatory cytokines, like TNFo, induce Muc5ac gene expression through activation of the NFKB pathway in lung epithelial cells [11]. NFkB is a major transcription factor essential for regulation of both innate and adaptive immunity, and inflammation. Inhibition of the $\mathrm{NF \kappa B}$ 
pathway resulted in attenuation of airway inflammation in asthma both in experimental models and in humans [12-14]. A putative NFkB site at $-3594 /-3581$ was identified in the promoter region of Muc5ac which is responsible for the increased Muc5ac expression following stimulation with inflammatory cytokines in airway epithelial cells [11].

Azathioprine is an immunosuppressive drug, which has been used for more than five decades to treat many inflammatory diseases [15-17]. Azathioprine is a pro-drug that is rapidly converted to 6-mercaptopurine (6-MP). As an immunosuppressive drug, 6-MP is widely used as a key agent in organ transplant recipients to prevent allograft rejection, as a maintenance drug for patients with inflammatory bowel disease, to treat rheumatoid arthritis, hematologic malignancies, chronic active hepatitis, and lupus nephritis [17]. 6-MP has been shown to have antiinflammatory effects through inhibiting prostaglandin synthesis and neutrophil trafficking into inflammatory tissue [18] and Rac1 inhibition in T cells and gut epithelial cells $[19,20]$. Several randomized trials reported that 6-MP led to improvement in patient's asthmatic symptoms, probably due to reducing airway inflammation [18]. It is also reported that 6-MP may be used as a steroid sparing agent for patients with asthma [18]. Prolonged treatment of 6-MP has also been shown to be effective in the treatment of chronic asthma patients [17]. 6-MP may reduce $\mathrm{T}$-cell activation and regulate the $\mathrm{T}$-helper (Th)1 response to maintain a balance between Th1 and Th2 response in asthma [21]. Despite its extensive use in many clinical studies in asthma, the molecular mechanism behind actions of 6-MP is poorly understood.

Given that 6-MP has both an anti-inflammatory function and an immune modulatory function, and also its association with treatment of chronic asthma in humans, we hypothesized that 6-MP may suppress mucus production through inhibition of the NFkB pathway in airway epithelial cells. Our results clearly demonstrate that 6-MP strongly inhibits cytokine synthesis and mucus production by reduced gene expression of Muc5ac through suppression of the NFkB pathway in airway epithelial cells.

\section{Methods}

\section{Cell culture and transfection}

Human mucoepidermoid carcinoma (NCI-H292) cells were grown and maintained in RPMI 1640 medium (Life Technologies) containing $10 \%$ FCS and $1 \%$ penicillin/ streptomycin. MLE-12 cells were grown in DMEM medium (Life Technologies) containing 5 \% FCS and $1 \%$ penicillin/streptomycin. For transient transfection experiments, cells were seeded at density of $2.4 \times 10^{4}$ cells $/ \mathrm{ml}$ and were transfected with indicated plasmids using Lipofectamine LTX plus transfection reagent (Life Technologies) according to manufacturer's instructions.

\section{MTT assay}

Cell viability was assessed by the MTT (3-[4, 5dimethylthiazol-2-yl]-2, 5-diphenyltetrazolium bromide) (Sigma) assay. Cells were seeded in a 96-well plate at a density of $2.4 \times 10^{3}$ cells/well and incubated overnight. Cells were made quiescent by incubation in medium without FCS for $24 \mathrm{~h}$ and then treated with vehicle (DMSO) or various concentrations of 6-MP (Sigma; 6-MP was dissolved in DMSO at a concentration of $10 \mathrm{mM}$ ) overnight followed by FCS $(10 \% \mathrm{v} / \mathrm{v})$ stimulation for $24 \mathrm{~h}$. After the incubation, cells were incubated with $10 \mu \mathrm{L}$ of MTT reagent $(5 \mathrm{mg} / \mathrm{ml})$ for $3 \mathrm{~h}$ at $37{ }^{\circ} \mathrm{C}$. The MTT reagent was removed, $100 \mu \mathrm{L}$ of isopropanol was added to each well and incubated for $15 \mathrm{~min}$. Colorimetric analysis was performed with an ELISA plate reader. Each experiment (in quadruplicate) was repeated at least three times.

\section{Semi-quantitative RT-PCR}

Semi-quantitative RT-PCR (RT-PCR) was performed as described previously [22, 23]. Briefly, cells were serumstarved for $24 \mathrm{~h}$ and were pre-treated overnight with 6-MP $(10 \mu \mathrm{M})$ or BAY-117085 (NFkB inhibitor; $10 \mu \mathrm{M}$ : Calbiochem). After the incubation, cells were stimulated with TNF $\alpha$ (R\&D systems; $50 \mathrm{ng} / \mathrm{ml}$ ) or PMA (Sigma; $1 \mathrm{nM})$ for $6 \mathrm{~h}$ before harvesting. Acidic ribosomal phosphoprotein P0 was used as a house-keeping gene. The analysis of the data involved the so called LinReg method described previously [24]. The following primers were used for RT-PCR: RANTES forw: 5'-CGCTGTC ATCCTCATTGC-3', RANTES rev: 5'-CCACTGGTGTAGAAATACTCC-3'; IL-6 forw: 5'-CGCCTTCGGTCC AGTTG-3', IL-6 rev: 5' - TCGTTCTGAAGAGGTGAG TG-3'; IL-12p35 forw: 5'- AGGAATGTTCCCATGCC TTCAC-3', IL-12 p35 rev: 5'- GCAACTCTCATTCT TGGTTAATTC-3'; TNF $\alpha$ forw: 5'-AGGACACCATGA GCACTGAAAG-3', TNF $\alpha$ rev: 5' -AGGAGAGGCTGAG GAACAAG-3'; IL-1 $\beta$ forw: 5'-TGGCAGAAAGGGAA CAGAAAGG-3', IL-1 $\beta$ rev: 5' - GTGAGTAGGAGAGG TGAGAGAGG-3'; Muc5ac forw: 5'-GGAACTGTGG GGACAGCTCTT-3', Muc5ac rev: 5'-GTCACATTCCT CAGCGAGGTC-3'; Muc2 forw: 5'-CAGCACCGATTG CTGAGTTG-3', Muc2 rev: 5' - GCTGGTCATCTCAAT GGCAG-3'; P0 forw: 5'-TCGACAATGGCAGCATCTA C-3', P0 rev: 5' -ATCCGTCTCCACAGACAAGG-3'.

\section{Western blot analysis}

Western blot analysis was performed as described previously [22, 23]. Antibodies applied in western blot analysis were phospho-specific (p)IkB $\alpha$ (Cell signaling; 1:500), and $\beta$-actin (Cell signaling; 1:1000).

\section{Periodic acid schiff staining}

To evaluate the production of mucus glycoproteins, Periodic Acid Schiff (PAS) staining was performed. Cells 
were serum-starved for $24 \mathrm{~h}$ and then stimulated with TNF $\alpha(50 \mathrm{ng} / \mathrm{ml})$ or PMA $(1 \mathrm{nM})$ for $24 \mathrm{~h}$. After the incubation, cells were fixed with formaldehyde for $30 \mathrm{~min}$ and mucus glycoconjugates were visualized by PAS staining. Hematoxylin staining was also incorporated as a counterstain.

\section{Luciferase assays}

Cells were transiently transfected with a NFkB reporter plasmid and a NFkB subunit p65 reporter plasmid using Lipofectamine LTX plus transfection reagent according to the manufacturer's protocol and assay was described previously [25]. The construct containing the $\mathrm{NFKB}$ response element of the minimal IL-6 promoter was kindly provided by Dr. Karolien De Bosscher (Ghent University, Belgium) and was described previously [26]. The pRL-TK Renilla reporter plasmid (Promega) was co-transfected as an internal control for transfection efficiency. Luciferase activity measurements were performed using the dualluciferase reporter assay system (Promega) and Glomax multi detection system (Promega) according to the manufacturer's protocol. Each experiment (in duplicate) was repeated at least three times.

\section{Immunofluorescence staining}

Cells were seeded on cover slips and serum-starved for $24 \mathrm{~h}$. After starvation, cells were treated with 6-MP overnight and then stimulated with TNF $\alpha(50 \mathrm{ng} / \mathrm{ml})$ for $24 \mathrm{~h}$. Cells were fixed with $4 \%$ (w/v) Formal-Fix (Thermo Scientific), washed and incubated with Muc5ac antibody (Santa Cruz; 1:500). Following repeated washing steps with PBS, protein localization was visualized by secondary antibodies coupled to fluorescent dyes Alexa Fluor-568 or -488 (Molecular Probes). Nuclei were counterstained with Hoechst (Molecular Probes).

\section{Statistical analysis}

All statistical analyses were carried out with GraphPad Prism software (GraphPad Software, San Diego, Calif). Comparisons between two groups were done with the Student $t$ test for unpaired variables. Comparisons between more than two groups were analyzed by ANOVA. Data are reported as mean \pm SD. $P$ values $<0.05$ were considered as statistically significant.

\section{Results}

\section{Effect of 6-MP on airway epithelial cell viability}

6-MP is an immunosuppressive drug and is known to associate with inhibition of proliferation of cells such as T-lymphocytes, smooth muscle cells, endothelial cells and intestinal epithelial cells, we sought to investigate the effect of 6-MP on viability of airway epithelial cells $[19,27-30]$. To study this, a MTT assay was performed using various concentrations of 6-MP in mucoepidermoid carcinoma NCI-H292 cells. We found that 6-MP has no effect on cell proliferation at concentrations up to $15 \mu \mathrm{M}$, however it inhibits cell proliferation at a concentration of $20 \mu \mathrm{M}$ (Fig. 1). No cell cytotoxicity was observed at concentrations up to $15 \mu \mathrm{M}$ (data not shown). Therefore, we chose to study the effect of 6-MP at $10 \mu \mathrm{M}$ in the following experiments as it was also shown to be effective in our previous studies with gut epithelial cells [19, 29].

\section{Inhibition of the inflammatory response of airway epithelial cells by 6-MP}

We and others previously demonstrated that 6-MP decreases the inflammatory response in various cells such as endothelial cells, smooth muscle cells and gut epithelial cells $[19,29,30]$. As inflammation is also a key event in airway diseases, we investigated the effect of 6-MP on inflammation in NCI-H292 cells. 6-MP significantly decreased TNFo-induced mRNA expression of several proinflammatory cytokines such as RANTES, IL-6, IL-12, and TNF $\alpha$, but not IL-1 $\beta$ (Fig. 2). In addition, 6-MP decreases PMA-induced mRNA expression of cytokines in NCI-H292 cells (Additional file 1: Figure S1E-F). Similar data were obtained in mouse alveolar epithelial MLE-12 cells (Additional file 1: Figure S1A-B). Altogether, these data indicate that 6-MP has an anti-inflammatory function in airway epithelial cells.

\section{6-MP inhibits activation of the NFKB pathway}

$N F \kappa B$ is a pleiotropic transcription factor that is activated in response to inflammatory cytokines, mitogens, and infections in airway epithelial cells [11]. Having established that 6-MP inhibits activation of the NFKB pathway in endothelial cells [29], and based on its profound inhibitory effect on inflammatory response in

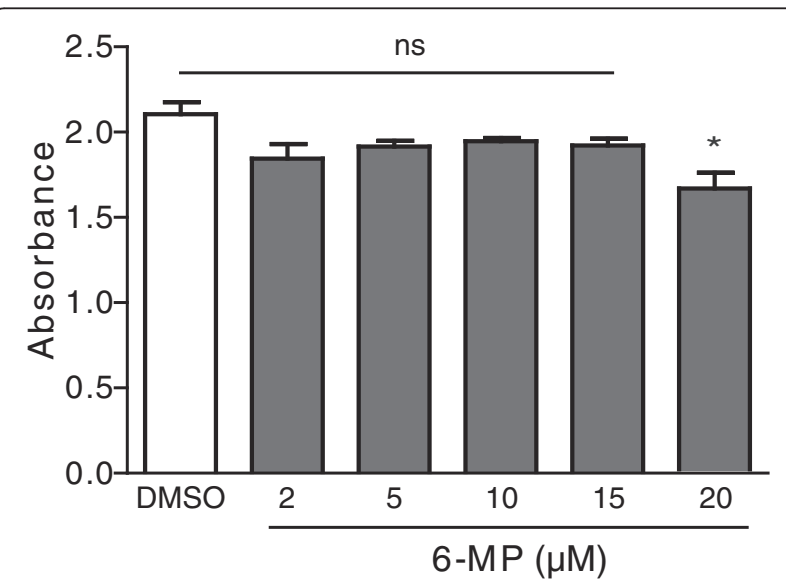

Fig. 1 Effect of 6-MP on airway epithelial cell viability. Serum-starved $\mathrm{NCl}-\mathrm{H} 292$ cells were pre-treated with 6-MP at the indicated concentrations and MTT assays were performed to assess cell proliferation. Values represent mean \pm S.D. ${ }^{*}, p \leq 0.05$; ns = non-significant 

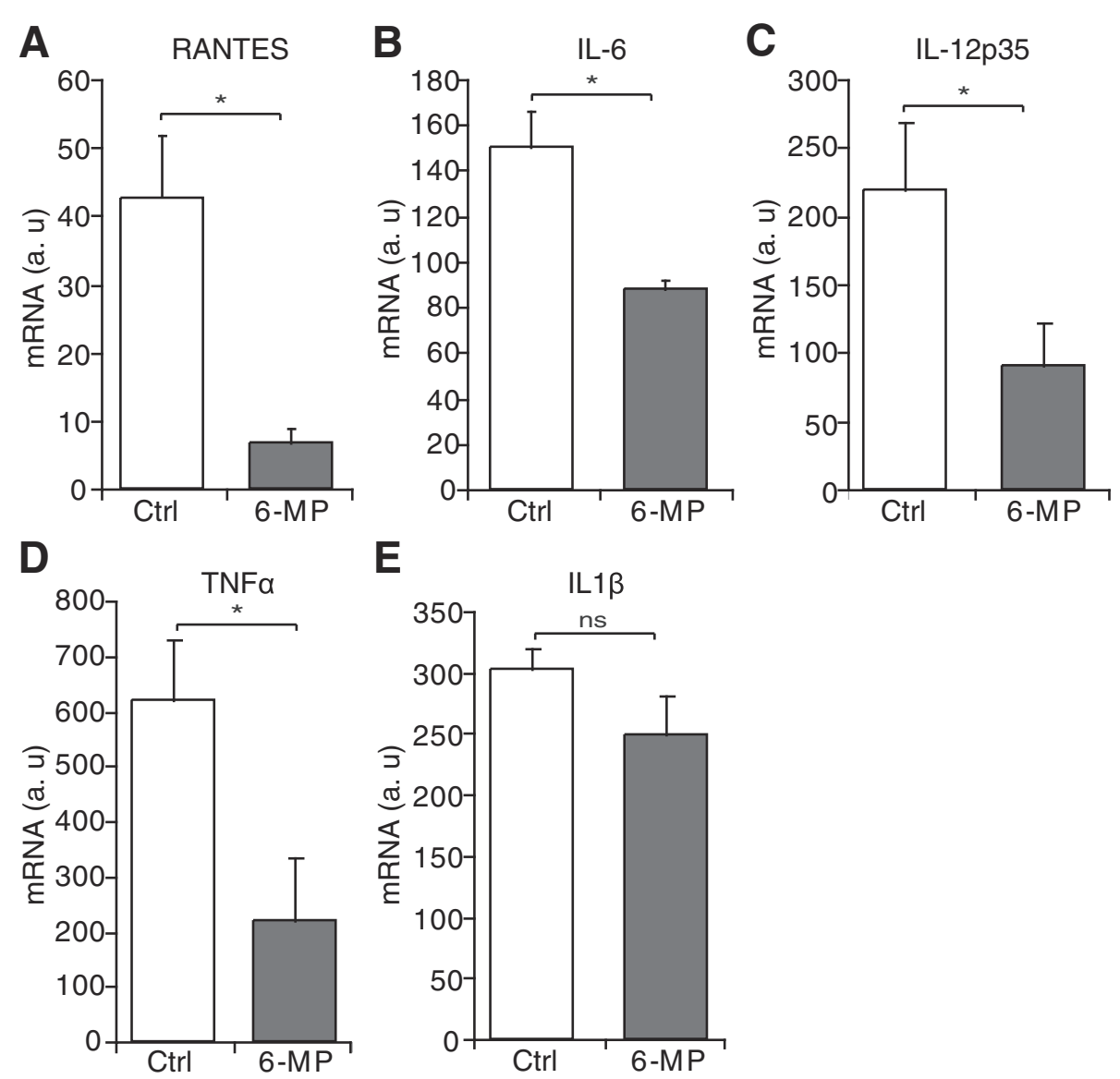

Fig. 2 6-MP decreases the inflammatory response in airway epithelial cells. Serum-starved NCI-H292 cells were pre-treated with 6-MP and then stimulated with TNFa for 6 h. RT-PCR was performed to assess mRNA expression of RANTES (a), IL-6 (b), IL-12p35 (c), TNFa (d), and IL-1ß (e). Values represent mean \pm S.D. ${ }^{*}, p \leq 0.05$. a.u = arbitrary units

NCI-H292 cells, we hypothesized that 6-MP inhibits the NFkB pathway in NCI-H292 cells. NCI-H292 cells were serum-starved for $24 \mathrm{~h}$ and pretreated with 6-MP followed by stimulation with TNF $\alpha$ for the indicated time points. Western blot analysis shows that 6-MP inhibits TNF $\alpha$-induced phosphorylation of $\operatorname{IkB} \alpha$, an inhibitory unit of NFkB (Fig. 3a). To corroborate these findings, we performed a luciferase assay using an $\mathrm{NF \kappa B}$ luciferase reporter plasmid. Consistent with the above findings, 6-MP significantly reduced TNF $\alpha$-induced NFkB activity in NCI-H292 cells (Fig. 3b). Previous studies showed that 6-MP exhibits an anti-inflammatory function through inhibition of the NFKB subunit p65 in a rat model of subarachnoid hemorrhage [31]. Therefore, we investigated the effect of 6-MP on cells overexpressing the NFkB subunit p65. We found that 6-MP attenuates p65 activity indicating that 6 -MP directly affects the transcriptional activity of $\mathrm{NFkB}$ (Fig. 3c). In addition, 6-MP decreases PMA-induced NFKB activity in MLE-12 cells (Additional file 1: Figure S1C). In endothelial cells and gut epithelial cells, 6-MP inhibits Rac1 activity
$[19,29]$. As a measure of Rac1 activity GTP-bound Rac1 was measured in MLE-12 cells and show to be reduced by 6-MP (Fig. 3d). Taken together, these data demonstrate that 6-MP reduces the inflammatory response through inhibition of the NFkB pathway at different levels.

\section{6-MP attenuates Muc5ac mucin gene expression}

Numerous studies reported that the NFKB pathway is involved in regulation of Muc5ac gene expression in airway epithelial cells [11]. Indeed, we also found that an NFKB inhibitor markedly decreased mRNA expression of TNF $\alpha-$ induced Muc5ac mucin gene expression in NCI-H292 cells, confirming the previously published results (Fig. 4a). Since 6-MP reduces activation of the $\mathrm{NFK}_{\mathrm{K}} \mathrm{B}$ pathway, we hypothesized that 6-MP may regulate Muc5ac gene expression. To test our hypothesis, we performed RTPCR analyses for Muc5ac gene expression following treatment with 6-MP. As expected, we found that 6-MP significantly decreased TNF $\alpha$-and PMA-induced Muc5ac gene expression (Fig. 4b; Additional file 1: Figure S1D). In addition to Muc5ac, Muc2 is also associated with inflammatory 

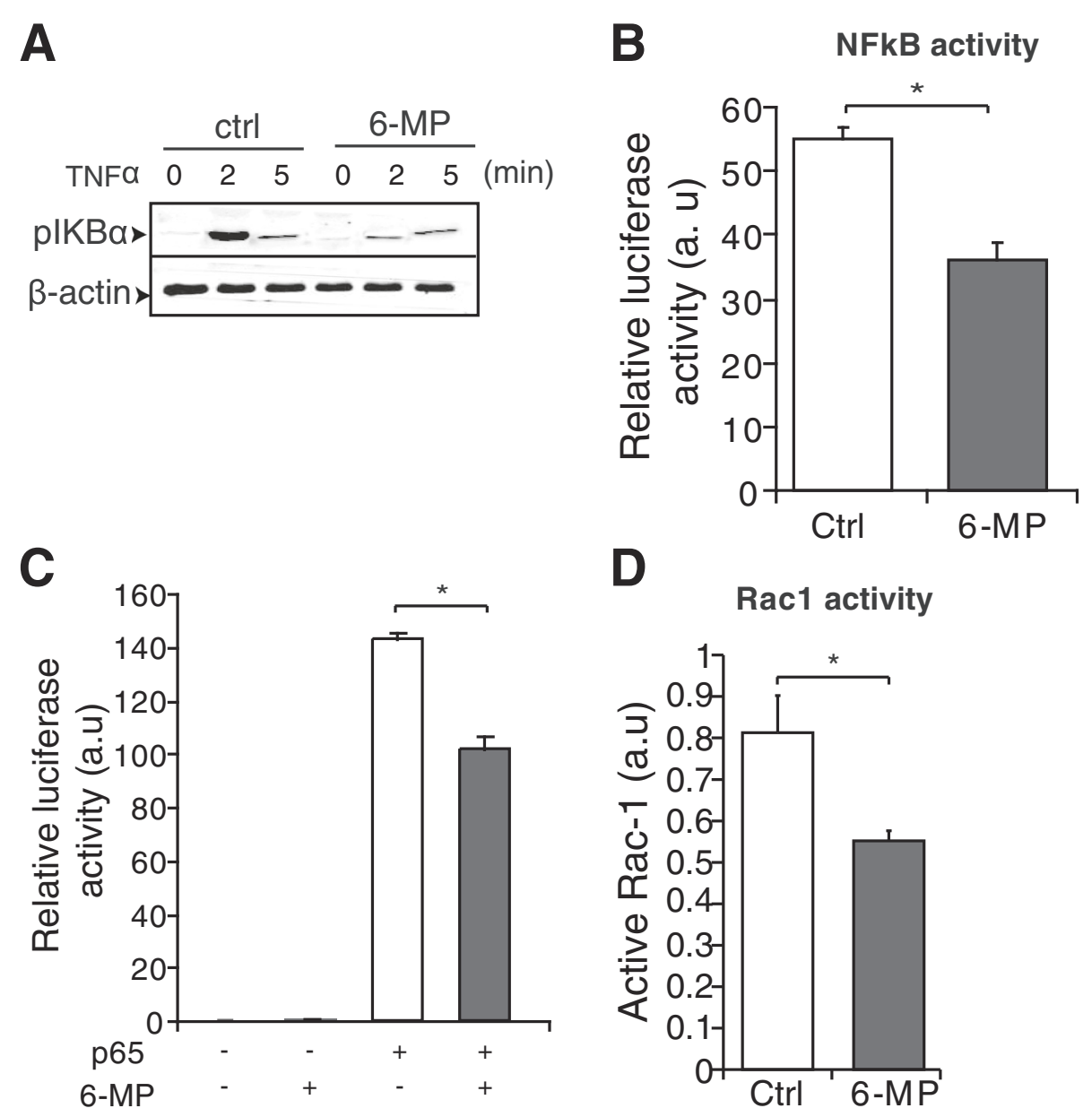

Fig. 3 6-MP inhibits activation of the NFKB pathway. a Serum-starved NCl-H292 cells were pre-treated with 6-MP and then stimulated with TNFa for the indicated time periods. Western blot analysis for plkBa was performed and $\beta$-actin was used as a loading control. $\mathbf{b}$ NCl-H292 cells were transfected with a NFKB-reporter plasmid and TNFa-induced luciferase activity was measured in the absence and in the presence of 6-MP. c The NFKB subunit p65 was overexpressed together with the NFKB-reporter plasmid and luciferase activity was measured after 36 h. The transfection efficiencies were normalized using Renilla luciferase co-transfection. d Rac1 activity is decreased by 6-MP in MLE-12 cells. Values represent mean \pm S.D. ${ }^{*}, p \leq 0.05$. a.u = arbitrary units

airway diseases such as chronic bronchitis, and cystic fibrosis $[32,33]$. We therefore analyzed the mRNA expression of Muc2, but 6-MP has no effect on the mRNA expression of Muc2, suggesting the selective regulation of Muc5ac by 6-MP (Fig. 4c). We next investigated the effect of 6-MP on Muc5ac protein expression using an immunofluorescent assay. Consistent with mRNA data of Muc5ac, 6-MP strongly inhibits the TNF $\alpha$-induced Muc5ac protein expression (Fig. 4d). Altogether, we conclude from these experiments that 6-MP-mediated inhibition of NFKB reduces Muc5ac gene expression.

\section{Mucus production is decreased by 6-MP}

To further substantiate above findings, we performed PAS staining to test whether 6-MP has any effect on overall mucus production. Serum-starved NCI-H292 cells were pretreated with 6-MP followed by stimulation with PMA or TNFa. Similar to TNFa, PMA has also been shown to induce mucus production in airway epithelial cells [34]. In line with reduced Muc5ac gene expression, 6-MP markedly attenuated mucus production in the untreated, PMA- and TNF $\alpha$-stimulated NCIH292 cells (Fig. 5).

\section{Discussion}

Excessive mucus production is an important hallmark of airway diseases such as asthma, cystic fibrosis, and chronic obstructive pulmonary disease [8]. A promising approach to attenuate airway inflammation is identification and development of a useful drug that inhibits secretion and production of mucins, the major constituents of airway mucus. 6-MP is an immunosuppressive drug and was reported to exhibit various biological effects such as anti-inflammatory and immunomodulatory functions 

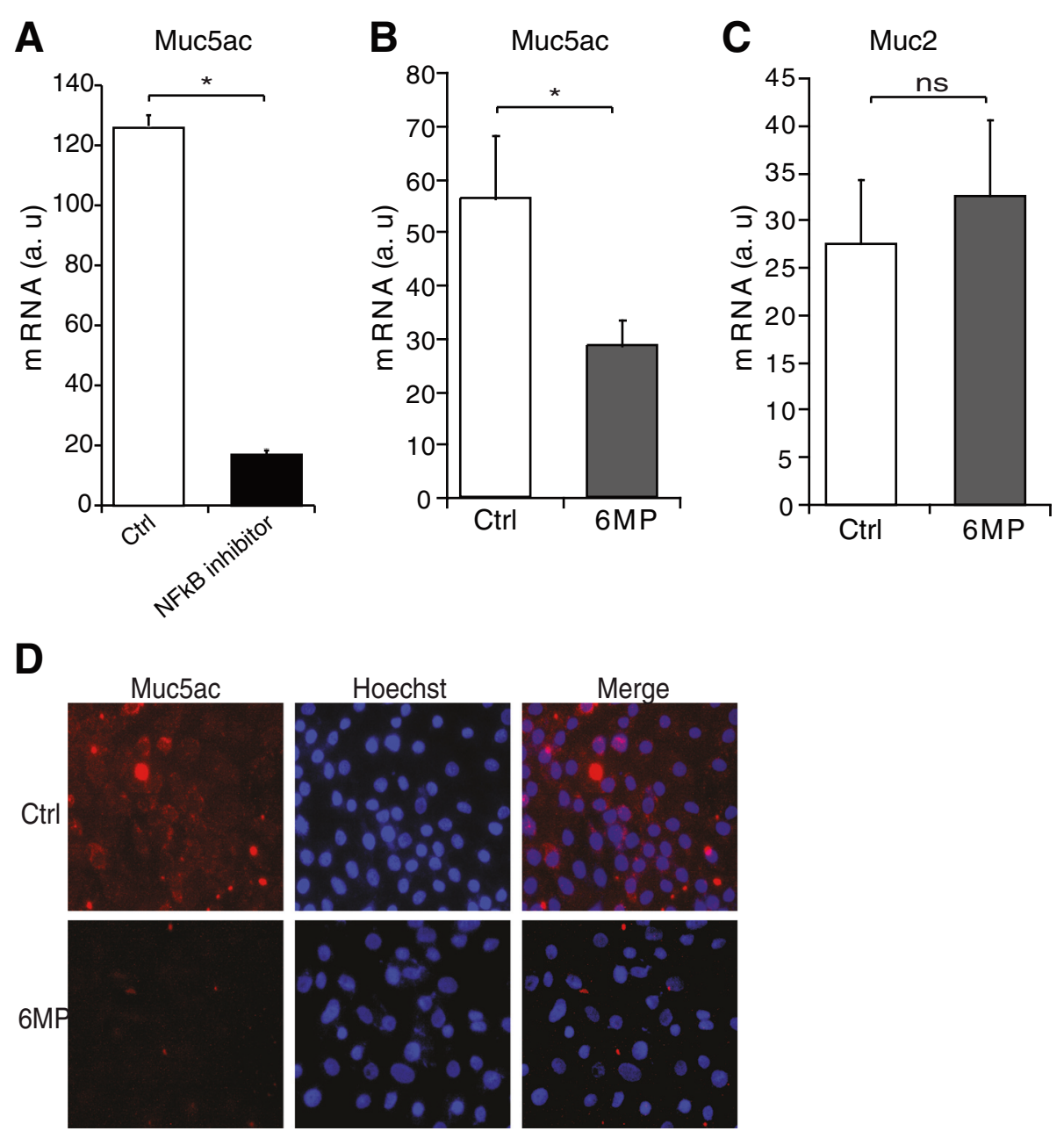

Fig. 4 6-MP decreases Muc5ac mucin gene expression. a Serum-starved NCI-H292 cells were treated with a NFkB inhibitor and then stimulated with TNFa. RT-PCR was performed to assess mRNA expression of Muc5ac. b-c Serum-starved NCI-H292 cells were pre-treated with 6-MP and then stimulated with TNFa, and RT-PCR was performed to assess mRNA expression of Muc5ac (b) and Muc2 (c). Values represent mean \pm S.D. * ${ }^{*} p \leq 0.05$. d Muc5ac protein expression was determined by immunofluorescence using the appropriate antibody, and Hoechst was used for nuclear staining. a.u $=$ arbitrary units

[19, 20, 29]. Although 6-MP has been used to treat asthmatic patients, its function as well as the mechanism responsible for its action on airway epithelial cells is unknown. In this study, we investigated the potential effect of 6-MP on mucin gene expression and mucus production in airway epithelial cells. For these studies, we chose human NCI-H292 mucoepidermoid carcinoma and mouse lung epithelial MLE-12 cells, widely used model systems to study mucin production, because various inflammatory stimuli induce mucin gene transcription in these cells [35]. We demonstrated, to the best of our knowledge for the first time, that 6-MP significantly reduces both TNF $\alpha$ - and PMA-induced Muc5ac mucin gene expression and mucus production through inhibition of airway inflammation mediated by NFkB pathway.
As an immunosuppressive drug, 6-MP has been shown inhibit proliferation of different cells such as lymphocytes, smooth muscle cells, endothelial cells and intestinal epithelial cells [19, 27-30]. Our present data demonstrate that 6-MP has no effect on the proliferation of lung airway cells, however 6-MP exhibits cytotoxic effects at concentrations above $15 \mu \mathrm{M}$. Intestinal epithelial cells are more sensitive to $6-\mathrm{MP}$, as a $10 \mu \mathrm{M}$ concentration was shown to inhibit the proliferation of these cells [19], which may require further research.

Allergic asthma is well characterized by mucus hypersecretion and airway inflammation which eventually leads to airway obstruction [5-7]. Airway epithelial cells, in addition to other cells such as dendritic cells, airway smooth muscle cells and lymphocytes, contribute to airway inflammation in asthma involving 


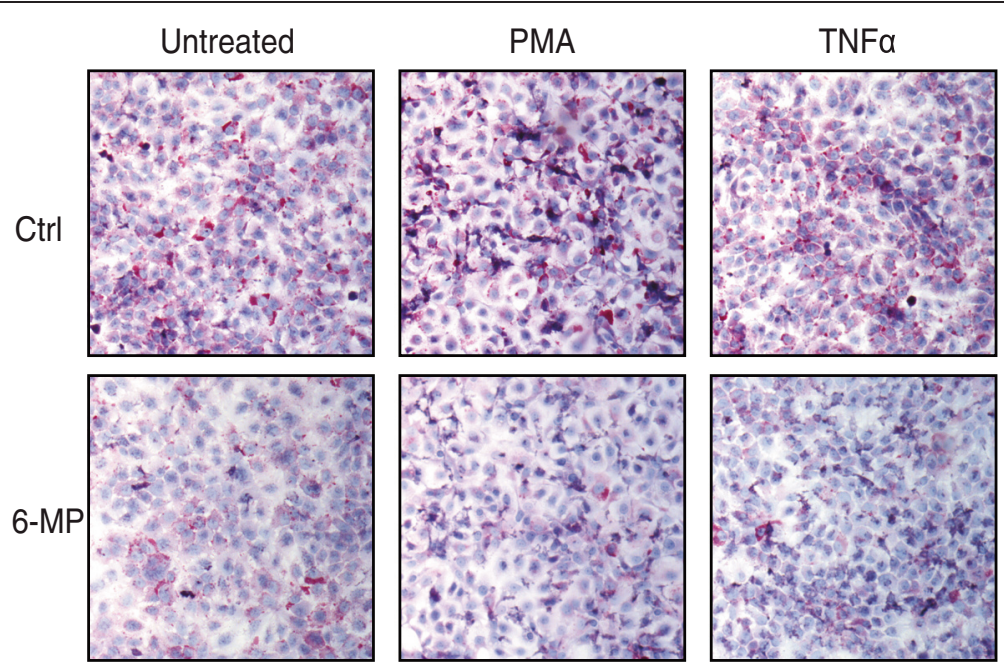

Fig. 5 6-MP inhibits mucus production in airway epithelial cells. Serum-starved NCI-H292 cells were treated with 6-MP and then stimulated with PMA or TNFa. Mucus glycoconjugates were visualized by PAS staining. Hematoxylin staining was incorporated as a counterstain to visualize the nuclei

enhanced activation of the $\mathrm{NF}_{k} \mathrm{~B}$ pathway. NFkB is a crucial regulator of inflammation and immunity, and is activated in bronchiolar epithelium both in humans and mice [12-14]. Inhibition of NFKB activity has been associated with a strong down-regulation of many of the molecular events that culminate in airway inflammation and structural damage of the lung in asthma. 6-MP has been demonstrated to be effective in the treatment of inflammatory diseases such as inflammatory bowel disease, rheumatoid arthritis and asthma, probably through modulation of the NFKB pathway $[17,29,31]$. Our present data further extend these findings showing that 6-MP attenuates expression of several proinflammatory cytokines, which are down-stream targets of NFkB, in airway epithelial cells. We demonstrate that 6-MP decreases Rac1 activation, similarly as in other cell types, however, in lung epithelial cells this did not result in apoptosis as was observed in T cells [20]. Given that Rac1 is an inducer of ІкB $\alpha$ phosphorylation, 6-MP inhibits this phosphorylation resulting in reduced NFkB activity in airway epithelial cells. The mere fact that overexpressed p65 as well as PMA-induced NFKB activity is lowered may indicate that 6-MP also has a more direct inhibitory effect on NFkB, for which at present the exact underlying mechanism is unknown.

Airway epithelial cells produce mucins, a class of mucus glycoproteins, that are crucial in maintaining epithelium homeostasis [3]. Under diseased conditions such as asthma, exaggerated airway epithelial mucin production leads to mucous plugging and ultimately to death [8]. Although other mucins are present, Muc5ac is a major constituent of airway mucus in humans $[9,10]$. It is well documented that multiple inflammatory stimuli such as TNF $\alpha$ induce the expression of Muc5ac through activation of NFKB in airway epithelial cells [11]. We have shown here that 6-MP attenuates TNF $\alpha$-induced Muc5ac gene expression and mucus production in NCI-H292 cells. Even though Muc2, like Muc5ac, contains an NFkB response element in its promoter [36], 6-MP failed to suppress Muc2 gene transcription. Apparently, the signaling pathways to induce Muc2 expression are different from those of Muc5ac, also demonstrating the selective regulation of 6-MP on Muc5ac. To gain insight on the effect of 6-MP on overall mucus production, PAS stainings were performed, revealing a dramatic decrease. 6-MP strongly inhibits both TNF $\alpha$ - and PMA-induced mucus production probably through inhibition of $\mathrm{NFKB}$ pathway. Although we did not investigate the expression of all known mucins, one may suggest that, in addition to Muc5ac, there are more 6-MP sensitive mucin genes.

\section{Conclusions}

In summary, we demonstrated that the immunosuppressive drug 6-MP inhibits inflammatory response induced by TNF $\alpha$ in human NCI-H292 and mouse MLE-12 lung cells. In addition, 6-MP attenuates TNF $\alpha$-induced Muc5ac expression and total mucus production through inhibition of activation status of Rac1 and I $\mathrm{B} \alpha \alpha$ phosphorylation resulting in reduced NFKB activation in NCI-H292 cells. The data presented in the current study disclosed a previously unknown role of 6-MP in airway epithelial cells as an efficacious mucoregulator. As these experiments were performed in cultured cells, results may not be generalizable to the airway epithelium in vivo and future studies should focus on testing of 6-MP in animal models of allergic airway inflammation. 


\section{Additional file}

Additional file 1: Figure S1. 6-MP decreases PMA-induced inflammatory response in airway epithelial cells. A-B; Serum-starved MLE-12 cells were pre-treated with 6-MP and then stimulated with PMA ( $1 \mathrm{nM}$ ) for $6 \mathrm{~h}$. RT-PCR was performed to assess mRNA expression of CXCL1 (A) and RANTES (B). C; MLE-12 cells were transfected with an NFKB-reporter plasmid and PMA-induced luciferase activity was measured in the in the presence of 6-MP. D-F; Serum-starved NCl-H292 cells were pre-treated with 6-MP and then stimulated with PMA (1 nM) for $6 \mathrm{~h}$. RT-PCR was performed to assess mRNA expression of Muc5ac (D), IL-1 $(E)$, and RANTES (F). Values represent mean \pm S.D; ${ }^{*}, p \leq 0.05$; a.u = arbitrary units.

\section{Abbreviations}

6-MP: 6-Mercaptopurine; FCS: Fetal calf serum; NFkB: Nuclear factor kappalight-chain-enhancer of activated B cells; PAS: Periodic Acid Schiff; TNF: Tumor necrosis factor

\section{Competing interests}

The authors declare that they have no competing interests.

\section{Authors' contributions}

Conception and design: KK, CJMV; Analysis and interpretation: KK, AAH, PL, CJMV; Drafting and writing the manuscript: KK, CJMV; Performing experiments and data collection: KK, AAH, PL, CJMV. All authors have approved the version of the submitted manuscript.

\section{Acknowledgments}

This work was supported by the research program of the BioMedical Materials institute, co-funded by the Dutch Ministry of Economic Affairs as a part of Project P1.02 NEXTREAM. This work was also supported by the Dutch Heart Foundation (grant No. 2008B037).

\section{Author details}

'Department of Medical Biochemistry, Academic Medical Center, University of Amsterdam, Meibergdreef 15, 1105 AZ Amsterdam, The Netherlands. ${ }^{2}$ Present address: Department of Molecular Cell Biology, Leiden University Medical Center, Leiden, The Netherlands.

\section{Received: 16 February 2015 Accepted: 10 June 2015}

\section{Published online: 19 June 2015}

\section{References}

1. Leikauf GD, Borchers MT, Prows DR, Simpson LG. Mucin apoprotein expression in COPD. Chest. 2002;121:166S-82.

2. Adler KB, Li Y. Airway epithelium and mucus: intracellular signaling pathways for gene expression and secretion. Am J Respir Cell Mol Biol. 2001;25:397-400

3. Lambrecht BN, Hammad H. The airway epithelium in asthma. Nat Med. 2012;18:684-92.

4. Kim WD. Lung mucus: a Clinician's view. Eur Respir J. 1997:10:1914-7.

5. Elias JA, Lee CG, Zheng T, Ma B, Homer RJ, Zhu Z. New insights into the pathogenesis of asthma. J Clin Invest. 2003;111:291-7.

6. Renauld JC. New insights into the role of cytokines in asthma. J Clin Patho 2001:54:577-89.

7. Wills-Karp M. Immunologic basis of antigen-induced airway hyperresponsiveness. Annu Rev Immunol. 1999:17:255-81.

8. Lundgren JD, Shelhamer JH. Pathogenesis of airway mucus hypersecretion. J Allergy Clin Immunol. 1990:85:399-417.

9. Evans CM, Kim K, Tuvim MJ, Dickey BF. Mucus hypersecretion in asthma: causes and effects. Curr Opin Pulm Med. 2009;15:4-11.

10. Reid CJ, Gould S, Harris A. Developmental expression of mucin genes in the human respiratory tract. Am J Respir Cell Mol Biol. 1997;17:592-8.

11. Fujisawa T, Velichko S, Thai P, Hung LY, Huang F, Wu R. Regulation of airway MUC5AC expression by IL-1 beta and IL-17A; the NF-KappaB paradigm. J Immunol. 2009:183:6236-43.

12. Hart LA, Krishnan VL, Adcock IM, Barnes PJ, Chung KF. Activation and localization of transcription factor, nuclear factor-KappaB, in asthma. Am J Respir Crit Care Med. 1998;158:1585-92.
13. Poynter ME, Cloots R, Van Woerkom T, Butnor KJ, Vacek P, Taatjes DJ, et al. NF-kappa B activation in airways modulates allergic inflammation but Not hyperresponsiveness. J Immunol. 2004;173:7003-9.

14. Tully JE, Hoffman SM, Lahue KG, Nolin JD, Anathy V, Lundblad LK, et al. Epithelial NF-KappaB orchestrates house dust mite-induced airway inflammation, hyperresponsiveness, and fibrotic remodeling. J Immunol. 2013;191:5811-21.

15. Connell WR, Kamm MA, Ritchie JK, Lennard-Jones JE. Bone marrow toxicity caused by azathioprine in inflammatory bowel disease: 27 years of experience. Gut. 1993:34:1081-5.

16. Hodges NG, Brewis RA, Howell JB. An evaluation of azathioprine in severe chronic asthma. Thorax. 1971;26:734-9.

17. Saadeh C, Urban RS. Azathioprine in the treatment of chronic refractory steroid-dependent asthma. South Med J. 1993:86:94-5.

18. Dean T, Dewey A, Bara A, Lasserson TJ, Walters EH. Azathioprine as an oral corticosteroid sparing agent for asthma. Cochrane Database Syst Rev. 2004:1:CD003270.

19. Marinkovic G, Hamers AA, de Vries CJ, de Waard V. 6-Mercaptopurine reduces macrophage activation and Gut epithelium proliferation through inhibition of GTPase Rac1. Inflamm Bowel Dis. 2014;20:1487-95.

20. Tiede I, Fritz G, Strand S, Poppe D, Dvorsky R, Strand D, et al. CD28-dependent Rac1 activation is the molecular target of azathioprine in primary human CD4+ T lymphocytes. J Clin Invest. 2003:111:1133-45.

21. Watanabe H, Uruma T, Tsunoda T, Ishii H, Tazaki G, Kondo T. Bronchial asthma developing after 15 years of immunosuppressive treatment following renal transplantation. Intern Med. 2012;51:3057-60

22. Kurakula K, Vos M, Otermin R,I, Marinkovic G, Buettner R, Heukamp LC, et al. The LIM-only protein FHL2 reduces vascular lesion formation involving inhibition of proliferation and migration of smooth muscle cells. PLOS ONE. 2014;9, e94931.

23. Kurakula K, Sommer D, Sokolovic M, Moerland PD, Scheij S, van Loenen PB, et al. LIM-only protein FHL2 is a positive regulator of liver $X$ receptors in smooth muscle cells involved in lipid homeostasis. Mol Cell Biol. 2015;35:52-62.

24. Ruijter JM, Ramakers C, Hoogaars WM, Karlen Y, Bakker O, van den Hoff M et al. Amplification efficiency: linking baseline and bias in the analysis of quantitative PCR data. Nucleic Acids Res. 2009;37, e45.

25. Kurakula K, van der Wal E, Geerts D, van Tiel CM, de Vries CJ. FHL2 protein is a novel Co-repressor of nuclear receptor Nur77. J Biol Chem. 2011;286:44336-43.

26. Plaisance S, Vanden Berghe W, Boone E, Fiers W, Haegeman G. Recombination signal sequence binding protein jkappa is constitutively bound to the NF-KappaB site of the interleukin-6 promoter and acts as a negative regulatory factor. Mol Cell Biol. 1997;17:3733-43.

27. Daniel PT, Holzschuh J, Muller CE, Roth HJ, Berg PA. Inhibition of phytohemagglutinine-induced T lymphocyte proliferation by 6-(octadecyldithio)purine, a novel liposomal prodrug of 6-mercaptopurine. Arch Toxicol Suppl. 1989;13:179-82.

28. Hibbins M, Inutsuka S, Chapman JR. Inhibition of PHA induced mononuclear cell proliferation by FK506 in combination with cyclosporine, methylprednisolone, 6-mercaptopurine and mycophenolic acid. Transpl Immunol. 1993;1:66-71.

29. Marinkovic G, Kroon J, Hoogenboezem M, Hoeben KA, Ruiter MS, Kurakula K, et al. Inhibition of GTPase Rac1 in endothelium by 6-mercaptopurine results in immunosuppression in nonimmune cells: New target for an Old drug. J Immunol. 2014;192:4370-8.

30. Pires NM, Pols TW, de Vries MR, van Tiel CM, Bonta PI, Vos M, et al. Activation of nuclear receptor Nur77 by 6-mercaptopurine protects against neointima formation. Circulation. 2007:115:493-500.

31. Chang CZ, Wu SC, Lin CL, Hwang SL, Kwan AL. Purine anti-metabolite attenuates nuclear factor KappaB and related Pro-inflammatory cytokines in experimental vasospasm. Acta Neurochir (Wien). 2012;154:1877-85.

32. Kim YD, Kwon EJ, Park DW, Song SY, Yoon SK, Baek SH. Interleukin-1 beta induces MUC2 and MUC5AC synthesis through cyclooxygenase-2 in $\mathrm{NCl}-\mathrm{H} 292$ cells. Mol Pharmacol. 2002;62:1112-8.

33. Levine SJ, Larivee $P$, Logun C, Angus CW, Ognibene FP, Shelhamer JH. Tumor necrosis factor-alpha induces mucin hypersecretion and MUC-2 gene expression by human airway epithelial cells. Am J Respir Cell Mol Biol. 1995;12:196-204 
34. Hewson CA, Edbrooke MR, Johnston SL. PMA induces the MUC5AC respiratory mucin in human bronchial epithelial cells, Via PKC, EGF/TGFalpha, Ras/Raf, MEK, ERK and Sp1-dependent mechanisms. J Mol Biol. 2004:344:683-95.

35. Rose MC, Voynow JA. Respiratory tract mucin genes and mucin glycoproteins in health and disease. Physiol Rev. 2006;86:245-78

36. Lee HW, Ahn DH, Crawley SC, Li JD, Gum Jr JR, Basbaum CB, et al. Phorbol 12-myristate 13-acetate Up-regulates the transcription of MUC2 intestinal mucin Via Ras, ERK, and NF-kappa B. J Biol Chem. 2002;277:32624-31.

Submit your next manuscript to BioMed Central and take full advantage of:

- Convenient online submission

- Thorough peer review

- No space constraints or color figure charges

- Immediate publication on acceptance

- Inclusion in PubMed, CAS, Scopus and Google Scholar

- Research which is freely available for redistribution 